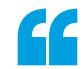

The tandem approach will inspire the development of other cooperative systems 5

\title{
Top tandem team
}

The electroreduction of $\mathrm{CO}_{2}$ and $\mathrm{H}_{2} \mathrm{O}$ into liquid fuels is a promising approach to mitigate $\mathrm{CO}_{2}$ emissions and meet the rising energy demand. However, the reduction of $\mathrm{CO}_{2}$ requires an input of energy and a catalyst to control the rates of formation and distribution of products. Now, reporting in Nature Catalysis, Christopher Hahn, Thomas Jaramillo and colleagues introduce a $\mathrm{Au}$ on $\mathrm{Cu}$ tandem catalyst that has unprecedented activity for the electroreduction of $\mathrm{CO}_{2}$ into multicarbon alcohols at room temperature and pressure.

To date, $\mathrm{Cu}$ is the only catalyst to demonstrate appreciable performance in the electrochemical reduction of $\mathrm{CO}_{2}$ to hydrocarbons and alcohols containing two or more carbon atoms $\left(\mathrm{C}_{2+}\right)$. This conversion is achieved in a multi-step process: $\mathrm{CO}_{2}$ is first reduced to $\mathrm{CO}$, and this intermediate is then reduced to predominantly hydrocarbons in subsequent reaction steps. "A major challenge in our search for materials more active than $\mathrm{Cu}$ has been discovering a single material with optimal catalytic properties for each and every one of the reaction steps," states Etosha Cave, a first author of the study. However, the team opened up the search to include bimetallic species composed of $\mathrm{Au}$ and $\mathrm{Cu}$, and revealed that the performance of a bimetallic catalyst can be superior to that of the constituent materials. "Coupling $\mathrm{Cu}$ to $\mathrm{Au}$, which is the most active metal for the first step of the reaction, relaxes constraints and enables $\mathrm{Cu}$ to focus on the downstream reaction steps," explains co-first author Carlos Morales-Guio.

Electron-beam deposition is used to deposit Au nanoparticles onto a polycrystalline $\mathrm{Cu}$ film to prepare the bimetallic $\mathrm{Au} / \mathrm{Cu}$ electrocatalyst. With $\mathrm{Au} / \mathrm{Cu}$ as the working electrode in an electrochemical cell, the performance of $\mathrm{Au} / \mathrm{Cu}$ for $\mathrm{CO}_{2}$ reduction can be measured and compared with that of either pure $\mathrm{Au}$ or $\mathrm{Cu}$ under the same conditions. At low overpotentials, the rate of conversion of

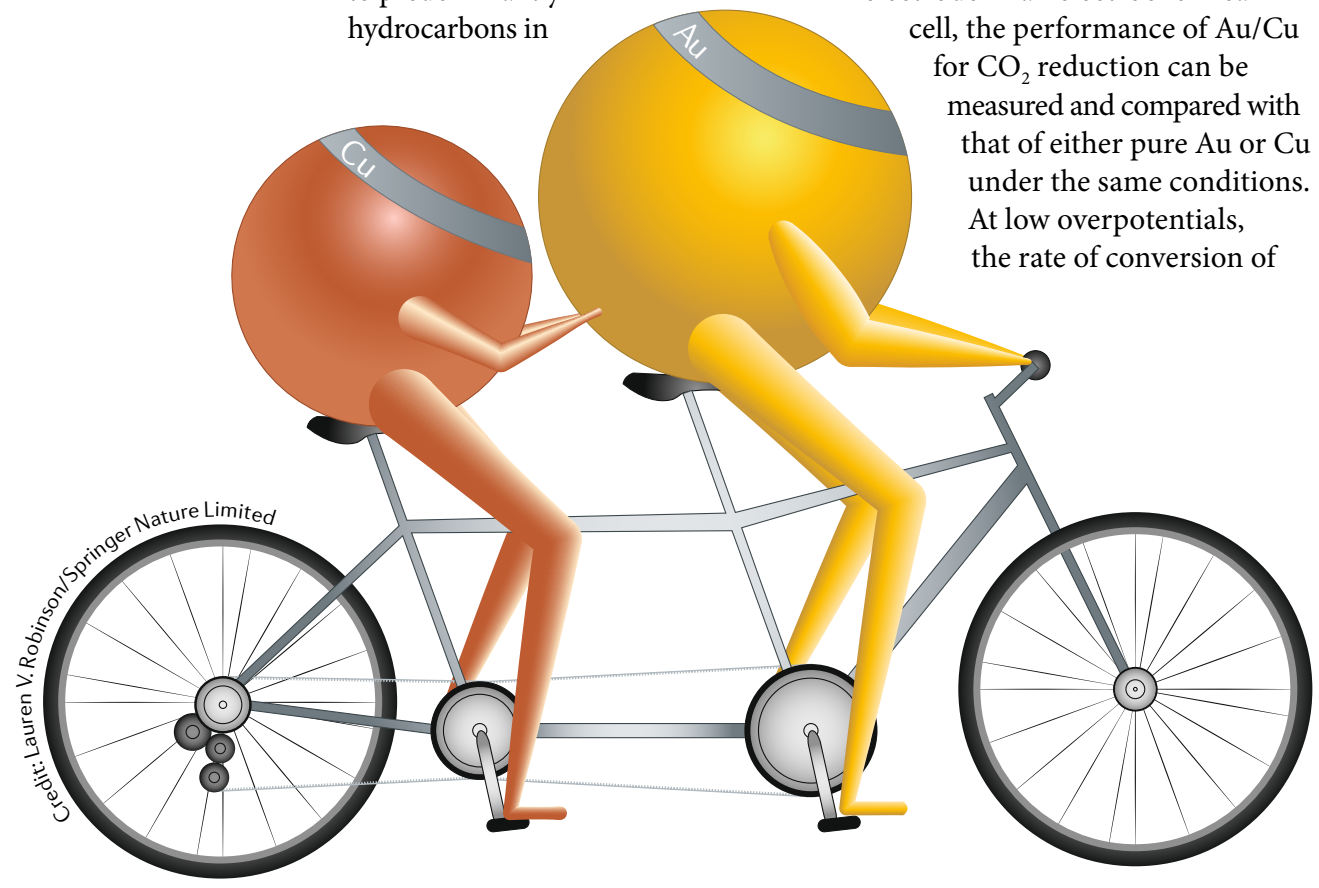

$\mathrm{CO}_{2}$ into products more reduced than $\mathrm{CO}$ is $>100$ times faster on $\mathrm{Au} / \mathrm{Cu}$ than on $\mathrm{Cu}$. Furthermore, unlike either $\mathrm{Cu}$ or $\mathrm{Au}$, at low overpotentials, $\mathrm{Au} / \mathrm{Cu}$ favours the production of $\mathrm{C}_{2+}$ alcohols, which are more desirable than hydrocarbons owing to their higher energy density. “ The bimetallic electrocatalyst shows synergistic activity, lowering the overpotential required to generate alcohols from $\mathrm{CO}_{2}$," summarizes Hahn.

The researchers propose a tandem catalysis mechanism for the reduction of $\mathrm{CO}_{2}$ on $\mathrm{Au} / \mathrm{Cu}$. In the initial step, $\mathrm{CO}_{2}$ is reduced to $\mathrm{CO}$ on the Au nanoparticles, generating a high local concentration of $\mathrm{CO}$. This $\mathrm{CO}$ then 'spills over' onto $\mathrm{Cu}$, where it is further reduced. Moreover, the team demonstrate that the nanoscale morphology and composition of the bimetallic catalyst is crucial in determining the product selectivity. For example, a AuCu alloy supressed alcohol formation, indicating that physical separation of Au and $\mathrm{Cu}$ is required to achieve selectivity for alcohols.

The team are exploring strategies to further increase the reaction rate, such as integrating $\mathrm{Au}$ nanoparticles onto high-surface-area $\mathrm{Cu}$ electrodes and the possibility of incorporating bimetallic $\mathrm{Au} / \mathrm{Cu}$ catalysts into vapour-fed reactors. "The tandem approach will inspire the development of other cooperative systems in which the active sites for sequential reaction steps are separated, allowing for unique catalytic behaviour," adds Jaramillo.

Claire Ashworth

ORIGINAL ARTICLE Morales-Guio, C.G.et al. Improved $\mathrm{CO}_{2}$ reduction activity towards $\mathrm{C}_{2+}$ alcohols on a tandem gold on copper electrocatalyst. Nat. Catalysis 1, 764-771 (2018) 